\title{
Accelerated growth of orbital schwannomas during pregnancy does not correlate with sex hormone- or growth factor receptor status
}

\section{G. J. Hötte, N. Meijer, R. M. Verdijk \& D. Paridaens}

To cite this article: G. J. Hötte, N. Meijer, R. M. Verdijk \& D. Paridaens (2020): Accelerated growth of orbital schwannomas during pregnancy does not correlate with sex hormone- or growth factor receptor status, Orbit, DOI: 10.1080/01676830.2020.1747498

To link to this article: https://doi.org/10.1080/01676830.2020.1747498

\section{曲 Published online: 08 Apr 2020.}

6 Submit your article to this journal

Џ Article views: 21

\section{Q View related articles $\longleftarrow$}

View Crossmark data $₫$ 


\title{
Accelerated growth of orbital schwannomas during pregnancy does not correlate with sex hormone- or growth factor receptor status
}

\author{
G. J. Hötte ${ }^{a *}$, N. Meijer ${ }^{a * \#}$, R. M. Verdijk ${ }^{a, b}$, and D. Paridaens ${ }^{a, c, d}$ \\ aDepartment of Oculoplastic, Orbital and Lacrimal Surgery, the Rotterdam Eye Hospital, Rotterdam, The Netherlands; ${ }^{\text {bDepartment of }}$ \\ Pathology, Section Ophthalmic Pathology, Erasmus MC University Medical Center Rotterdam, Rotterdam, The Netherlands; 'Department of \\ Ophthalmology, Orbital Service, Erasmus MC University Medical Center Rotterdam, Rotterdam, The Netherlands; ${ }^{\mathrm{d} O c u l o p l a s t i c ~ \& ~ O r b i t a l}$ \\ Service, ELZA Clinic, Zurich, Switzerland
}

\begin{abstract}
Purpose: Until now, three cases of growth of an orbital schwannoma during pregnancy have been published. We aim to provide additional insight in the effect of pregnancy on orbital schwannomas.

Methods: We present two additional cases of accelerated growth of orbital schwannomas during pregnancy and investigate receptor expression profiles for estrogen, progesterone, androgen, VEGF, EGF, FGF, PDGF-R $\beta$ and ki-67 in the two pregnant cases and six non-pregnant cases.

Results: Case 1: A 26-year-old woman developed unilateral exophthalmos during pregnancy, with normal visual acuity and ocular motility. During a subsequent pregnancy, again the exophthalmos progressed. MRI showed a mass suggestive of schwannoma. After delivery, resection of the lesion was performed through an anterior approach. Pathology confirmed schwannoma. The expression profile was positive for estrogen- and FGF receptors and ki-67, but negative for progesterone-, androgen- and other growth factor receptors. Case 2: A 24-year-old woman presented with diplopia and unilateral pain during pregnancy. She had normal visual acuity, but a mild exophthalmos and elevation deficit. MRI revealed an extraconal mass suggestive of schwannoma. After delivery, resection was performed through an anterior approach. Pathology confirmed the diagnosis. The expression profile was positive for ki-67, but negative for sex hormone- and growth factor receptors.

In the six non-pregnant cases the expression profiles varied, with only one subject showing a strong expression of estrogen-, progesterone- and androgen receptors.

Conclusions: Orbital schwannomas can experience growth during pregnancy. The underlying mechanism remains unclear as hormone- and growth factor expression profiles show no correlation to the pregnant state.
\end{abstract}

\section{ARTICLE HISTORY}

Received 2 November 2019

Accepted 20 March 2020

\section{KEYWORDS}

Growth factors; orbital schwannoma; pregnancy; receptors; sex hormones

\section{Introduction}

Orbital schwannomas were first described by Verocay in 1908. It is a rare benign neoplasm, accounting for approximately $1 \%$ of all orbital tumors, and arises from the myelin producing Schwann cells in peripheral axons. ${ }^{1}$

Most orbital schwannomas originate from the ophthalmic division of the trigeminal nerve and are commonly located in the superior orbit due to the nerve distribution pattern. ${ }^{2,3}$ It presents unilaterally, although there has been one report of bilateral orbital schwannoma. ${ }^{4}$ When small they are asymptomatic, but usually tend to grow over months to years, causing a slowly progressive exophthalmos and inferior displacement. ${ }^{3,5}$ Other clinical symptoms are also aspecific and include diplopia and motility disorders, visual loss, scotomas and eyelid swelling. ${ }^{3}$ Although they are usually painless, a deep, dull pain or sensibility disorder may occur in the distribution of the affected nerve. ${ }^{3}$ Schwannomas are predominantly benign, and reported cases of malignant transformation are controversial. ${ }^{5}$ Also, intracranial extension, most commonly through the superior orbital fissure, can occur. ${ }^{2}$

Imaging characteristics are best appreciated on magnetic resonance imaging (MRI), with a hypointense signal on $\mathrm{T} 1$ and a hyperintense signal on $\mathrm{T} 2$ weighted images. ${ }^{3,5}$ The use of contrast agents may show homogenous or heterogeneous enhancement. ${ }^{3,5}$

CONTACT G. J. Hötte g.hotte@oogziekenhuis.nl Department of Oculoplastic, Orbital and Lacrimal Surgery, The Rotterdam Eye Hospita, PO Box 70030, Rotterdam, LM 3000, The Netherlands

*These authors contriubuted equally to this work.

\#Present address: Department of Ophthalmology, Maastricht University Medical Center, Maastricht, The Netherlands

(c) 2020 Taylor \& Francis Group, LLC 
Macroscopically, orbital schwannomas appear as a vascularized, encapsulated mass. ${ }^{5}$ Histologically 5 subtypes are described: conventional-, cellular-, -, plexiform-, microcystic- and reticular schwannomas. Of these, conventional schwannomas are by far the most common type in the orbit. ${ }^{3}$ Longstanding tumors, which are referred to as ancient schwannomas, may also show degenerative changes such as hemorrhages, cyst-like spaces and calcification. ${ }^{3-5}$ Typically, two morphological patterns are noted, which are known as Antoni A and Antoni B areas. The Antoni A pattern shows closely packed spindle cells. The nuclei of Antoni A cells may also show a palisading pattern, known as Verocay bodies. In the Antoni B pattern, the spindle cells are more loosely arranged within the stroma. ${ }^{2,3,5,6}$ Interestingly, Pointdujour-Lim et al found that the Antoni B pattern corresponds to the lucent areas on $\mathrm{T} 1$ and hyperintense areas on T2-weighted MRI. ${ }^{2}$

The typical histological patterns can aid in the differentiation from other peripheral nerve sheath tumors. Immunohistochemistry is generally not required, but shows an intense diffuse staining profile for S-100., 3,8

Treatment consists of surgical excision. As the growth of schwannoma generally tends to displace the normal nerve eccentrically, the schwannoma may be dissected away from the involved nerve. ${ }^{2,5}$ If the lesion is incompletely excised, local recurrence may occur., ${ }^{5,9}$

To date, only three cases have reported accelerated growth of an orbital schwannoma during pregnancy. ${ }^{10-12}$ Chang et al reported that the tumor was positive for progesterone-, but not for estrogen receptors. ${ }^{11}$ The case presented by Sugo et al was negative for both progesterone- and estrogen receptors and Birkholz et al did not test for hormone receptor expression profiles. ${ }^{10,12}$ There are no reports on expression of non-sex hormone growth factor receptors for orbital schwannomas.

In this report we present two more cases of accelerated growth of orbital schwannomas during pregnancy. Also, we present receptor expression profiles for estrogen (ER), progesterone (PR), androgen (AR), vascular endothelial growth factor (VEGF-R), epidermal growth factor (EGF-R), fibroblast growth factor (FGF-R), platelet-derived growth factor (PDGF-R $\beta$ ) and the proliferation marker ki-67 and compare these to the expression profiles of six non-pregnant cases.

\section{Materials and methods}

Following the principles of the Declaration of Helsinki, the clinical course and expression profiles were evaluated in two orbital schwannomas experiencing growth during pregnancy. Additionally, in six non-pregnant cases the same expression profiles were assessed.

Diagnosis of orbital schwannoma was made based on histological characteristics, and incidental immunohistochemical staining for S-100. The expression profiles were evaluated for estrogen-, progesterone-, androgen receptor and ki-67 (respectively clone SP1, clone 1E2, clone SP107 and clone 30-9 from Ventana Medical Systems, Tucson, Arizona, USA). Cut-off levels for positive staining were arbitrarily put at $10 \%$ in analogy to generally accepted guidelines for the interpretation of hormone receptor staining in breast carcinoma. Likewise, receptor expression profiles were assessed for VEGF (clone SP28, abcam, ab27620), EGF (clone 3C6, Ventana), FGF (polyclonal, abcam, ab58201) and PDGF (receptor $\beta$, Santa Cruz, sc339). For these stainings an immunoreactive score (IRS) was determined as has been described in a previous report. ${ }^{13}$ First, intensity of the staining was classified as absent (0), mild (1), moderate (2) or intense (3). Secondly, percentage of stained cells that showed the predominant intensity was scored as no positive cells (0), less than $10 \%(1), 10 \%$ to $50 \%$ (2), $51 \%$ to $80 \%$ (3), and more than $80 \%$ (4). Finally, the IRS was determined as the product of intensity and percentage scores, thereby ranging from 0 tot 12 . Cutoff levels for positive IRS were arbitrarily put at 4 .

\section{Results \\ Case 1}

During pregnancy, a 26-year-old woman with a history of hypothyroidism, had noted an exophthalmos of her left eye and swelling of the left upper eyelid. After delivery of an unviable fetus, she was referred for further evaluation. Examination revealed an exophthalmos of $4 \mathrm{~mm}$ with inferior displacement of the globe (Figure 1a). Visual acuity and ocular motility were normal. There were no clinical signs of active Graves orbitopathy and both thyroid stimulating hormone (TSH) and fT4 were normal, although anti-TSH receptor antibodies were slightly elevated. No stigmata of neurofibromatosis were identified and no other neurological abnormalities were found.

MRI showed a well-defined cystic mass of $3.2 \times 1.5 \mathrm{~cm}$ with fluid levels. The lesion was located intraconally, extending to the extraconal space. The lesion showed contrast enhancement of the capsule only (Figure 1b). With the findings explained as cystic degeneration, the tumor was found most likely to be a schwannoma. 

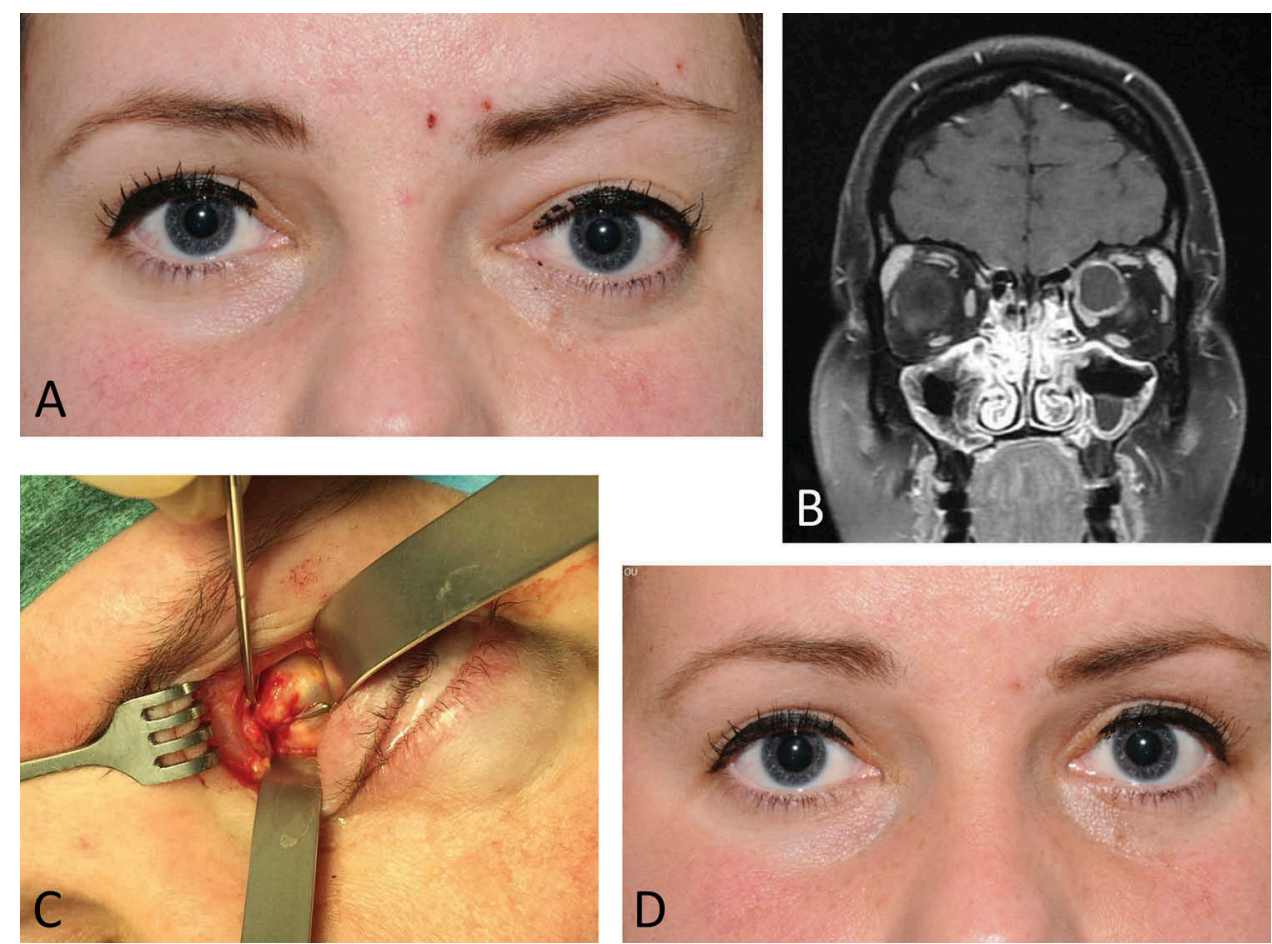

Figure 1. Case 1 (a) Pre-operative examination showed exophthalmos and inferior displacement of the left globe (b) T1-weighted MRI shows a well-defined cystic mass with contrast enhancement of the capsule only. (c) Intra-operative appearance of the schwannoma. (d) Post-operative examination showed no globe displacement.

Surgical excision was postponed because of a new pregnancy. During this pregnancy, the lesion again showed signs of growth with the exophthalmos reaching $8 \mathrm{~mm}$. Also, now there were complaints of obscurations in left gaze and a dull pain. After pregnancy, surgical resection was performed through a trans lid approach (Figure 1c). Post-operatively, examination showed no exophthalmos and normal visual acuity and ocular motility (Figure 1d). Also, there was no impairment of facial sensibility.

Histopathology revealed mainly areas of closely packed spindle cells, typical for the Antoni A pattern of schwannoma, and fewer areas of the Antoni B pattern (Figure 2a). Immunohistochemical studies showed that the tumor was diffusely and strongly positive for S-100, confirming the diagnosis (Figure $2 b$ ).

\section{Case 2}

A 24-year-old pregnant woman with no medical history presented with diplopia and pain of her right eye since the $19^{\text {th }}$ week of gestation. Examination showed a $2 \mathrm{~mm}$ exophthalmos of the right eye with inferior displacement of the globe. Orthoptic evaluation revealed a mild elevation deficit of the right eye. Visual acuity was normal. No neurological abnormalities were found and there was no family history of neurofibromatosis.

MRI was performed without contrast imaging and showed an extraconal mass of the right orbit (Figure 3a). The $3.5 \times 2 \mathrm{~cm}$ solid mass was located lateral to the superior rectus muscle and gave pressure to the levator palpebrae and superior rectus muscles. Based on these findings, the
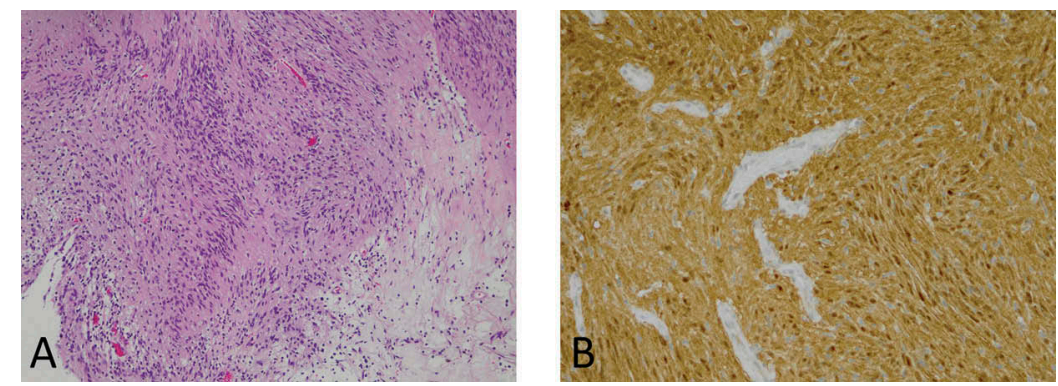

Figure 2. Case 1 (a) Hematoxylin-Eosin stain shows areas of tightly packed spindle cells (Antoni A) and areas of more loosely organized spindle cells (Antoni B). (B) Immunohistochemistry shows strong positive staining for S-100 protein. 

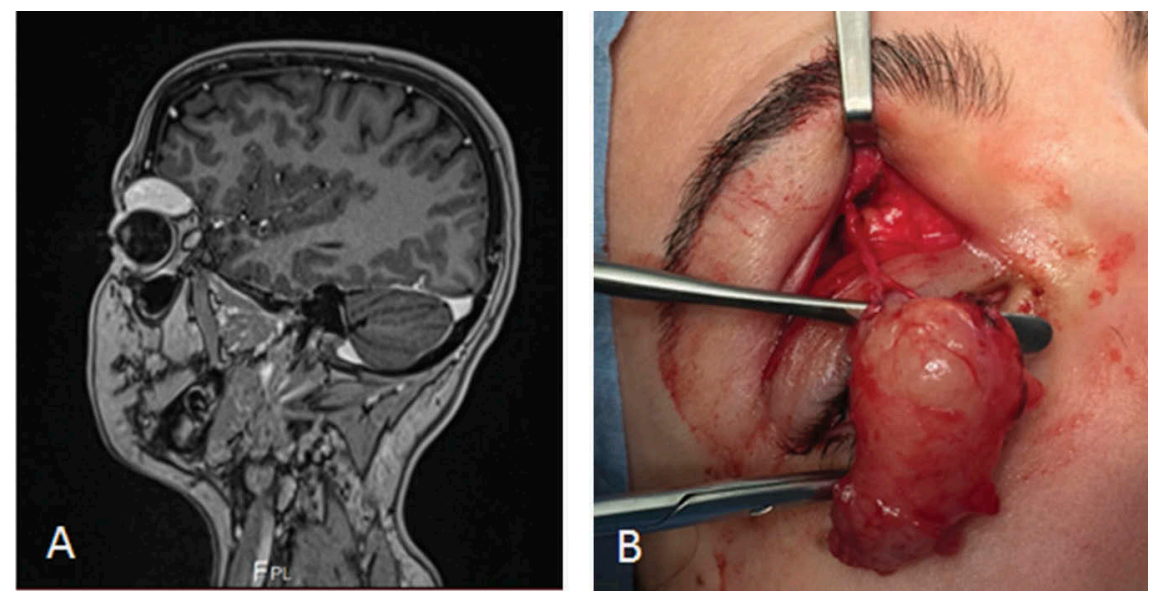

Figure 3. Case 2 (a) T1-weighted MRI without contrast shows an extraconal mass superior in the right orbit. (b) Intra-operative appearance of the schwannoma surrounding the supraorbital nerve.

lesion was suspected to be a schwannoma or cavernous hemangioma.

After an uneventful (term) delivery, surgical resection by a trans lid approach was performed. The tumor surrounded the supraorbital nerve, but could be resected completely (Figure $3 \mathrm{~b}$ ). Post-operatively, she experienced hypoesthesia in the region of the supraorbital nerve. Ocular motility and visual acuity were normal and there was no more exophthalmos.

Histopathology revealed abundant spindle cells and predominantly Antoni-A features. Immunohistochemical studies revealed a diffuse and strong positive staining for S-100 protein.

\section{Expression profiles for ER, PR, AR, VEGF-R, EGF-R, FGF-R, PDGF-R $\beta$ and ki-67}

For all eight cases the expression profiles for ER, PR, AR, VEGF-R, EGF-R, FGF-R, PDGF-R $\beta$ and ki-67 are depicted in Table 1.

In the first pregnant case, staining was negative for $\mathrm{PR}$ and AR but slightly positive for ER (Figure $4 a-c$ ). Conversely, the second pregnant case showed to be negative for all three sex hormone receptors (Figure $4 \mathrm{i}-\mathrm{k}$ ). Of the six non-pregnant subjects, the staining profiles showed mixed results, with one female case highly positive for ER, PR and AR (Figure 4q-s).

For the growth factors, only FGF-R came out positive in the first pregnant case (Figure $4 \mathrm{~d}-\mathrm{g}$ ), while none were positive in the second pregnant case (Figure 41-o). Again, results for the non-pregnant cases were mixed. Ki-67 was positive in both pregnant cases (Figure 4h,p), but in only one non-pregnant case.

\section{Discussion}

The levels of estrogen and progesterone show a steady increase during pregnancy until the moment of delivery. Some orbital neoplasms such as cavernous hemangiomas, solitary fibrous tumors and meningiomas, have shown a tendency to grow due to these hormonal changes or by the use of hormonal medication. ${ }^{14-18}$ In cavernous hemangioma, the tendency to grow during pregnancy could be explained by the expression of progesterone receptors. ${ }^{19,20}$ Moreover, for the acoustic schwannoma, growth during pregnancy has also been reported, but a correlation between progesterone- and estrogen receptor expression and proliferative activity could not be demonstrated. ${ }^{21-24}$

Table 1. Expression profiles.

\begin{tabular}{|c|c|c|c|c|c|c|c|c|c|}
\hline & Gender & ER & PR & AR & VEGF-R & EGF-R & FGF-R & PDGF-R $\beta$ & $k i-67$ \\
\hline Pregnant case 1 & $\mathrm{~F}$ & 10 & 0 & 2 & 1 & 0 & 4 & 3 & 15 \\
\hline Pregnant case 2 & $\mathrm{~F}$ & 2 & 1 & 0 & 0 & 0 & 0 & 1 & 10 \\
\hline Non-pregnant case 1 & M & 10 & 0 & 25 & 0 & 4 & 2 & 2 & 8 \\
\hline Non-pregnant case 2 & $\mathrm{~F}$ & 95 & 95 & 95 & 2 & 12 & 4 & 3 & 2 \\
\hline Non-pregnant case 3 & M & 1 & 20 & 12 & 1 & 4 & 2 & 2 & 8 \\
\hline Non-pregnant case 4 & M & 12 & 60 & 60 & 1 & 2 & 4 & 4 & 2 \\
\hline Non-pregnant case 5 & $\mathrm{~F}$ & 1 & 0 & 5 & 2 & 9 & 9 & 3 & 8 \\
\hline Non-pregnant case 6 & $\mathrm{~F}$ & 10 & 20 & 25 & 0 & 8 & 4 & 8 & 15 \\
\hline Expression rate & & $5 / 8(62.5 \%)$ & $4 / 8(50 \%)$ & $5 / 8(62.5)$ & $0 / 8(0 \%)$ & $5 / 8(62.5)$ & $5 / 8(62.5 \%)$ & $2 / 8(25 \%)$ & $3 / 8(37.5 \%)$ \\
\hline
\end{tabular}

ER = Estrogen Receptor; PR = Progesterone Receptor; AR = Androgen Receptor; VEGF-R = Vascular Endothelial Growth Factor Receptor; EGF-R = Epidermal Growth Factor Receptor; FGF-R = Fibroblast Growth Factor Receptor; PDGF-R $\beta$ = Platelet-derived Growth Factor Receptor- $\beta$. 


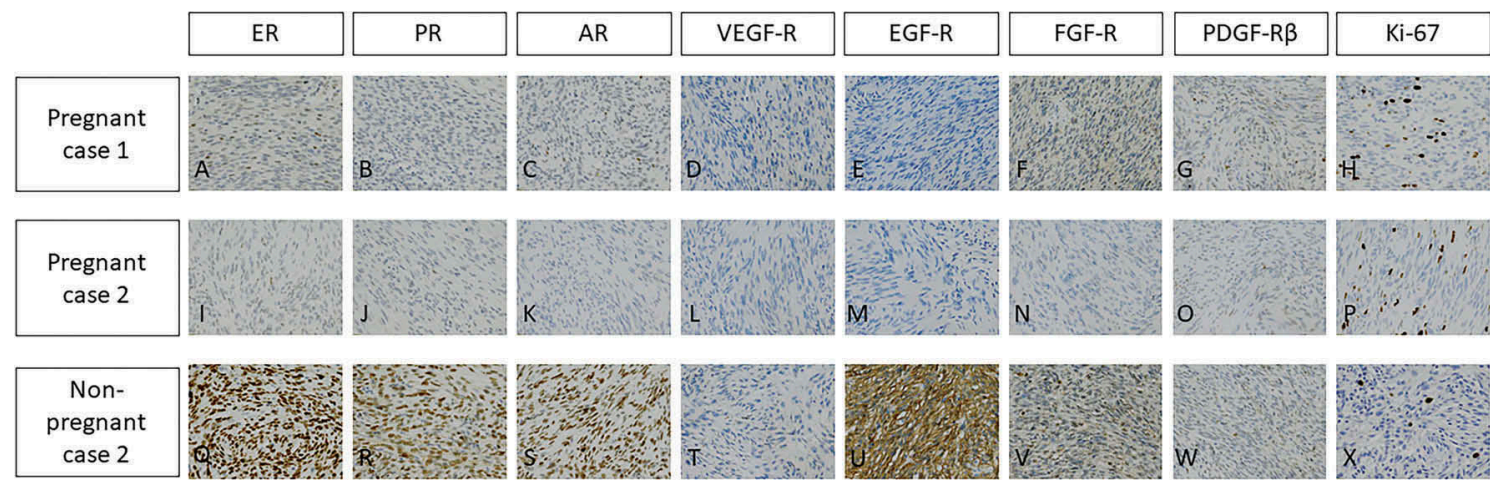

Figure 4. Staining profiles for receptors. ER = Estrogen Receptor; PR = Progesterone Receptor; AR = Androgen Receptor; VEGF-R $=$ Vascular Endothelial Growth Factor Receptor; EGF-R = Epidermal Growth Factor Receptor; FGF-R = Fibroblast Growth Factor Receptor; PDGF-R $\beta=$ Platelet-derived Growth Factor Receptor- $\beta$.

$(a-h)$ For the first pregnant case, staining was slightly positive for ER (a), FGF-R (f) and ki-67 (h).(i-p) For the second pregnant case, staining was slightly positive for ki-67 only (p).(q-x) In one non-pregnant case, also female, staining was strongly positive for ER (q), PR (r), AR (s) and EGF-R (u) and slightly positive for FGF-R (v)

On the other hand, vascular changes, possibly related to the expression of VEGF, have been shown to be an additional causative mechanism for growth of meningiomas during pregnancy. ${ }^{25,26}$ Also, the expression of other growth factor receptors, such as FGF-R and PDGF-R $\beta$, may be involved. ${ }^{27}$

For orbital schwannoma it is unclear what may cause excessive growth during pregnancy and little is known about receptor expression of these tumors. To date, three cases have reported accelerated growth of an orbital schwannoma during pregnancy. ${ }^{10-12}$ In their patient, Chang et al reported that the tumor was positive for progesterone-, but not for estrogen receptors. Based on this observation, they concluded that growth during pregnancy was to be explained by the expression of these progesterone receptors. ${ }^{12}$ On the other hand, the case presented by Sugo et al was negative for both progesterone- and estrogen receptors. As such, they suggested that another factor, such as intratumoral hemorrhage, may have explained the accelerated growth. They state that this assumption was supported by the presence of erythrocyte components in the cystic fluid. ${ }^{11}$ Indeed, schwannomas are known to be highly vascularized, putting them at risk for such intratumoral hemorrhage. However, the presence of erythrocyte components is a normal finding in schwannomas and does not further support their hypothesis. Unfortunately, Birkholz et al did not test for the expression of hormone receptors in their patient. $^{10}$

In this report we have evaluated the receptor expression profiles for sex hormones (ER, $P R$ and $A R$ ), growth factors (VEGF-R, EGF-R, FGF-R, PDGF-R $\beta$ ) and the proliferation marker ki-67 in two pregnant and six non-pregnant subjects with orbital schwannomas.

For the expression of sex hormone receptors, our first pregnant case showed expression of only ER, while the second case was negative for all three hormone receptors. One control case however, did show highly increased expression of all three hormone receptors. As such, our series fail to show a direct correlation between the receptor expression profiles of ER, PR and $\mathrm{AR}$ and the tendency to grow during pregnancy.

When looking at the expression of growth factor receptors, the first pregnant case showed expression of only FGF-R, while again, the second case was negative for all four growth factor receptors. In the nonpregnant cases the results were mixed, with EGF-R and FGF-R being most predominantly expressed. Again, no correlation can be drawn between these expression profiles and the accelerated growth during pregnancy.

As suggested by Sugo et al, other factors that may explain the sudden growth should be sought. ${ }^{11}$ Nevertheless, especially the first case (with a positive expression of ER and FGF-R) is an interesting one, as she experienced tumor growth during two sequential pregnancies without signs of intratumoral hemorrhage. Also, as ki-67 is cellular marker for proliferation, the positive expression of ki-67 in both pregnant cases implicates an active proliferative state at the time of surgery. ${ }^{28}$ Interestingly, of the six non-pregnant cases, one case showed a very strong expression of all three sex hormone and EGF receptors, but no expression of ki-67. It must be said, however, that there was no indication about recent growth in the non-pregnant subjects, which may explain low ki-67 expression in 
these cases. This limits the value of our comparison between pregnant and non-pregnant cases.

Overall, the expression rates were $62.5 \%$ for ER, $50 \%$ for PR, $62.5 \%$ for AR, $0 \%$ for VEGF-R, $62.5 \%$ for EGFR, $62.5 \%$ for FGF-R, 25\% for PDGF-R $\beta$ and $37.5 \%$ for ki-67. Moreover, no evident difference in staining patterns could be identified when looking at male and female subjects separately.

In conclusion, orbital schwannomas can show accelerated growth during pregnancy, which has been suggested to be associated with sex hormone receptor expression. Our current series show no correlation between tumor growth during pregnancy and receptor expression profiles of ER, PR, AR, VEGF-R, EGF-R, FGF-R and PDGF-R $\beta$, although the expression of ki67 does implicate an active proliferative state of these tumors.

\section{Acknowledgments}

The authors wish to thank Thierry van den Bosch for performing the immunohistochemical stainings.

\section{Disclosure statement}

The authors report no conflicts of interest. The authors alone are responsible for the content and writing of the article.

\section{References}

1. Shields JA, Shields CL, Scartozzi R. Survey of 1264 patients with orbital tumors and simulating lesions: the 2002 montgomery lecture, part 1. Ophthalmology. 2004;111(5):997-1008. doi:10.1016/j.ophtha.2003. 01.002 .

2. Pointdujour-Lim R, Lally SE, Shields JA, Eagle RC Jr., Shields CL. Orbital Schwannoma: radiographic and histopathologic correlation in 15 cases. Ophthalmic Plast Reconstr Surg. 2018;34(2):162-167. doi:10.1097/ IOP.0000000000000900.

3. Sweeney AR, Gupta D, Keene CD, Cimino PJ, Chambers CB, Chang S-H, et al. Orbital peripheral nerve sheath tumors. Surv Ophthalmol. 2017;62 (1):43-57. doi:10.1016/j.survophthal.2016.08.002.

4. Sales-Sanz M, Sanz-Lopez A, Romero JA. Bilateral simultaneous ancient schwannomas of the orbit. Ophthalmic Plast Reconstr Surg. 2007;23(1):68-69. doi:10.1097/IOP.0b013e31802d97dd.

5. Kim KS, Jung JW, Yoon KC, Kwon YJ, Hwang JH, Lee SY. Schwannoma of the orbit. Arch Craniofac Surg. 2015;16(2):67-72. doi:10.7181/acfs.2015.16.2.67.

6. Grossniklaus HE, Eberhart CG, Kivelä TT. WHO classification of tumours of the eye. Vol. 12. 4th ed; 2018. IARC.

7. Nakamura Y, Becker LE, Marks A. Distribution of immunoreactive S-100 protein in pediatric brain tumors. J Neuropathol Exp Neurol. 1983;42 (2):136-145. doi:10.1097/00005072-198303000-00003.

8. Weiss SW, Langloss JM, Enzinger FM. Value of S-100 protein in the diagnosis of soft tissue tumors with particular reference to benign and malignant Schwann cell tumors. Lab Invest. 1983;49:299-308.

9. Chisholm IA, Polyzoidis K. Recurrence of benign orbital neurilemmoma (schwannoma) after 22 years. Can J Ophthalmol. 1982;17:271-273.

10. Birkholz ES, Lee AG, Nerad JA, Lane KA, Bilyk JR. A pregnant pause. Surv Ophthalmol. 2010;55 (2):162-168. doi:10.1016/j.survophthal.2009.03.007.

11. Sugo N, Yokota K, Nemoto M, Hatori T, Kano T, Goto S, et al. Accelerated growth of an orbital schwannoma during pregnancy. J Neuroophthalmol. 2007;27 (1):45-47. doi:10.1097/WNO.0b013e3180321426.

12. Chang BY, Moriarty P, Cunniffe G, Barnes C, Kennedy S. Accelerated growth of a primary orbital schwannoma during pregnancy. Eye (Lond). 2003;17 (7):839-841. doi:10.1038/sj.eye.6700475.

13. van Ipenburg JA, de Waard NE, Naus NC, Jager MJ, Paridaens D, Verdijk RM. Chemokine receptor expression pattern correlates to progression of conjunctival melanocytic lesions. Invest Ophthalmol Vis Sci. 2019;60 (8):2950-2957. doi:10.1167/iovs.19-27162.

14. Cowppli-Bony A, Bouvier G, Rue M, Loiseau $\mathrm{H}$, Vital A, Lebailly $\mathrm{P}$, et al. Brain tumors and hormonal factors: review of the epidemiological literature. Cancer Causes Control. 2011;22(5):697-714. doi:10.1007/ s10552-011-9742-7.

15. Das JK, Sharma AS, Deka A, Das D. Solitary fibrous tumor of the orbit presenting in pregnancy. Indian J Ophthalmol. 2009;57(3):238-240. doi:10.4103/03014738.49405.

16. Hyde RA, Liu Y, Aakalu VK, Setabutr P. Solitary fibrous tumor of the orbit with growth during pregnancy: a case report. Orbit. 2019 Jun;38(3):256-258. doi:10.1080/01676830.2018.1474930.

17. Lee BJ, Schoenfield L, Perry JD. Orbital intramuscular hemangioma enlarging during pregnancy. Ophthalmic Plast Reconstr Surg. 2009;25(6):491-493. doi:10.1097/ IOP.0b013e3181b80c42.

18. Zauberman H, Feinsod M. Orbital hemangioma growth during pregnancy. Acta Ophthalmol (Copenh). 1970;48 (5):929-933. doi:10.1111/j.1755-3768.1970.tb08213.x.

19. Di Tommaso L, Scarpellini F, Salvi F, Ragazzini T, Foschini MP. Progesterone receptor expression in orbital cavernous hemangiomas. Virchows Arch. 2000;436 (3):284-288. doi:10.1007/s004280050042.

20. Gupta A, Prabhakaran VC, Dodd T, Davis G, Selva D. Orbital cavernous haemangiomas: immunohistochemical study of proliferative capacity, vascular differentiation and hormonal receptor status. Orbit. 2012;31 (6):386-389. doi:10.3109/01676830.2012.711887.

21. Beatty CW, Scheithauer BW, Katzmann JA, Roche PC, Kjeldahl KS, Ebersold MJ. Acoustic schwannoma and pregnancy: a DNA flow cytometric, steroid hormone receptor, and proliferation marker study. Laryngoscope. 1995;105(7):693-700. doi:10.1288/00005537-19950700000005 .

22. Beni-Adani L, Pomeranz S, Flores I, Shoshan Y, Ginosar Y, Ben-Shachar I. Huge acoustic neurinomas 
presenting in the late stage of pregnancy. Treatment options and review of literature. Acta Obstet Gynecol Scand. 2001;80:179-184.

23. Kachhara R, Devi CG, Nair S, Bhattacharya RN, Radhakrishnan VV. Acoustic neurinomas during pregnancy: report of two cases and review of literature. Acta Neurochir (Wien). 2001;143(6):587-591. doi:10.1007/s007010170063.

24. Sharma JB, Pundir P, Sharma A. Acoustic neuroma in pregnancy: emergency cesarean section and definitive neurosurgery. Int $J$ Gynaecol Obstet. 2003;80 (3):321-323. doi:10.1016/S0020-7292(02)00342-9.

25. Hortobagyi T, Bencze J, Murnyak B, Kouhsari MC, Bognar L, Marko-Varga G. Pathophysiology of meningioma growth in pregnancy. Open Med (Wars). 2017;12:195-200. doi:10.1515/med-2017-0029.

26. Lusis EA, Scheithauer BW, Yachnis AT, Fischer BR, Chicoine MR, Paulus W, et al. Meningiomas in pregnancy: a clinicopathologic study of 17 cases. Neurosurgery. 2012;71 (5):951-961. doi:10.1227/NEU.0b013e31826adf65.

27. Smith JS, Quinones-Hinojosa A, Harmon-Smith M, Bollen AW, McDermott MW. Sex steroid and growth factor profile of a meningioma associated with pregnancy. Can J Neurol Sci. 2005;32(1):122-127. doi:10.1017/S0317167100017017.

28. Sun X, Kaufman PD. Ki-67: more than a proliferation marker. Chromosoma. 2018;127(2):175-186. doi:10.1007/ s00412-018-0659-8. 